\title{
Capital in context: Funding U.S. Inland Northwest food hub development before and during COVID-19
}

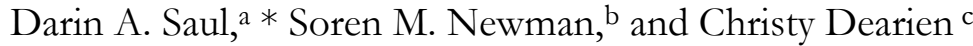 \\ University of Idaho
}

Submitted April 6, 2021 / Revised July 2, 2021 / Accepted September 23, 2021 / Published online December 17, 2021

Citation: Saul, D. A., Newman, S. M., \& Dearien, C (2021). Capital in context: Funding U.S. Inland Northwest food hub development before and during COVID-19. Journal of Agriculture, Food Systems, and Community Development, 11(1), 153-169. https://doi.org/10.5304/jafscd.2021.111.016

Copyright (C 2021 by the Authors. Published by the Lyson Center for Civic Agriculture and Food Systems. Open access under CC-BY license.

\begin{abstract}
This study focuses on how 10 food hubs in the U.S. Inland Northwest resourced their start-up and development before and during the first year of the COVID-19 pandemic. Case studies include cooperative, government agency, nonprofit, and familyowned food hubs. Because of the prominence of nonmonetary values as drivers in food hub development, we used a social entrepreneurship framework to understand how people, context, and a social value proposition affected access to and use

a * Corresponding author: Darin A. Saul, Director, Office of Grant and Project Development, College of Agricultural and Life Sciences, University of Idaho; 875 Perimeter Drive; Moscow, Idaho 83844 USA; +1-208-885-1536; dsaul@,uidaho.edu

b Soren M. Newman, Senior Researcher, Office of Grant and Project Development, College of Agricultural and Life Sciences, University of Idaho; 875 Perimeter Drive; Moscow, Idaho 83844 USA; newman@,uidaho.edu

${ }^{c}$ Christy Dearien, Research Associate, Office of Grant and Project Development, College of Agricultural and Life Sciences, University of Idaho; 875 Perimeter Drive; Moscow, Idaho 83844 USA; cdearien@uidaho.edu
\end{abstract}

of capital resources. We found that each food hub had a unique mix of capital sources and profitability that reflected and shaped who was involved, their mission, and their available resources. All operating food hubs that we studied strengthened and grew their business during the first year of the pandemic. Two federal COVID-19-related programs - the Paycheck Protection Program and the Farmers to Families Food Box Program-played brief but instrumental roles in helping most organizations early in the pandemic, enabling several to pivot from heavily impacted markets (such as restaurants and educational institutions) to directto-consumer markets and food security efforts. For several, panic buying early in the crisis followed by

\section{Author Note}

The authors do not have potential conflicts to declare. Darin A. Saul and Soren M. Newman also wrote five case studies of organizations included in this paper as part of a food hub feasibility study for the Walla Walla Valley, Washington.

\section{Funding Disclosure}

This work was supported by the USDA Agriculture and Food Research Initiative under grants 2014-68006-21866 and 201868006-28102. 
a consistent large increase in demand fueled organizational growth. The food hubs adapted quickly, with some significantly changing their business model and expected trajectory as they weathered the first year of the pandemic, coming out stronger than before.

\section{Keywords}

Food Systems, Local, COVID-19, Pandemic, Food Security, Social Entrepreneurship, Community, Rural, Grants, Paycheck Protection Program, PPP, Farmers to Families Food Box Program

\section{Introduction}

Food hubs are becoming key players in developing and coordinating local and regional place-based food supply chains throughout the United States. The number of food hubs recognized by the U.S. Department of Agriculture (USDA) increased approximately 83\%, from 139 in 2009 to 254 in 2021 (Neal, 2017; USDA, Agricultural Marketing Service, 2021). While U.S. food hubs have a relatively high survival rate $88 \%$ survived from 2005 to 2017 compared to a 53\% survival rate for all types of new businesses) (Feldstein \& Barham, 2017), some end in costly failures, and many efforts in various stages of planning and investment never launch (e.g., Morgan, 2015). The importance of establishing a strong financial model from the start is a critical lesson learned from food hubs that have closed (Feldstein \& Barham, 2017). The COVID-19 pandemic has drastically impacted food distribution needs, challenges, and resources, requiring swift and nimble response and repositioning by distributors (Blacher \& Fields-Kyle, 2021; Ollove \& Hamdi, 2021). At this point, little is known about the financial resilience of food hubs in the pandemic and its impact on their business trajectory.

The USDA, Agricultural Marketing Service (2021) defines food hubs as "businesses or organizations that actively manage the aggregation, distribution, and marketing of source-identified food products to multiple buyers from multiple producers, primarily local and regional producers, to strengthen the ability of these producers to satisfy local and regional wholesale, retail, and institutional demand" (para. 1). Although this definition focuses on providing access to wholesale markets, food hubs in practice have more diverse business models. While $39 \%$ of food hubs responding to the 2019 National Food Hub Survey primarily focused on wholesale markets, $22 \%$ focused on direct-toconsumer sales, and another third focused on both (Bielaczyc et al., 2020). Food hubs also have various legal business structures: in 2019, 17\% were cooperatives, $40 \%$ were nonprofits, and $36 \%$ were for-profits (Bielaczyc et al., 2020). Food hubs provide more than economic opportunities for small and midsized farms. Most aim to advance social and environmental goals: Bielaczyc et al. (2020) found only $12 \%$ did not identify social and environmental goals as important. Another form of nonprofit food hub is the community-based organization, which focuses on "developing the capacity of producers they support, and creating infrastructure that supports and maintains market access for them" (Matson et al., 2013, p. 9).

Nonmonetary values are often important drivers in food hub development, even among more profit-driven food hubs (Ostrom et al., 2017). To address this focus on nonmonetary values, we use components of the social entrepreneurship framework, advanced by Austin, Stevenson, and WeiSkillern (2006), to explore how people, context, and a social value proposition reflect and shape access to and use of capital as part of resource mobilization during food hub development. The model considers people's skills, attitudes, knowledge, contacts, experience, and values that contribute to success (Austin et al., 2006). Context is critical in understanding the impact of factors outside the entrepreneur's control, of which the COVID-19 pandemic provides an exceptional example. We consider social value proposition in terms of how mission reflects and shapes resource availability and development trajectory. These factors contribute to the deal, which defines who does what and who benefits. The deal in a social enterprise transaction includes not only economic benefits, but also altruistic goals, social recognition, autonomy, and satisfaction of personal needs (Austin et al., 2006). These, in turn, shape the opportunities in which entrepreneurs invest resources for future financial, social, and personal returns. Opportunity is not necessarily perceived 
the same by different participants, and a common challenge is developing a shared definition of opportunity to create motivation for joint action (Austin et al., 2006). According to Austin et al. (2006), social entrepreneurship often relies on a range of capital sources. The 2019 National Food Hub Survey reflected this diversity. Food hubs reported revenues from federal, state, and local government; foundations; donations; member fees; rents; other business income; and in-kind support (Bielaczyc et al., 2020).

The social enterprise food hubs that Avetisyan and Ross (2019) studied started by identifying a need or issue and then recruited stakeholders and partners willing to contribute, which largely determined the resources available for the start-up. Profitability was still important, and while social goals were their long-term mission, the short-term goal was to generate enough revenue to operate. One of the hubs studied by Avetisyan and Ross (2019) began as a profit-driven business and then refocused on social values as it developed, demonstrating that different values may manifest at different stages. Through this integration of long-term social goals and short-term business goals, food hubs can create social change and meet social needs, as well as offer financial opportunity for producers and other private businesses (Avetisyan \& Ross, 2019).

This study draws on 10 U.S. Inland Northwest food hub case studies. We focus on the evolution of their business strategies before and during the first year of the COVID-19 pandemic to understand (1) how they funded the start and scale-up of their operations, (2) how they adapted during the pandemic, and (3) lessons learned that could support food hub success and survival throughout the country. We consider how a critical mass of capital from diverse sources is recruited as part of food hub start-up and development and how this differs for cooperative, government agency, nonprofit, and private family food hubs.

In the following, we describe our study area and methods before briefly presenting each food hub, organized by business model. Next, we discuss the role of capital and its relationship with context, people, and social value proposition and the impact of the COVID-19 pandemic on food hub business trajectory. Finally, we conclude by identifying implications for practice and research.

\section{Methods}

We conducted 10 case studies of food hubs representing different scales, services, models, and development stages in the U.S. Inland Northwest. We chose this area because we wanted to study local and regional food system development in rural areas typical of the U.S. West (Figure 1). The Cascade Mountains to the west insulate the Inland Northwest from the dense populations of Portland (Oregon) and Vancouver, Seattle, and Tacoma (Washington), making the Inland Northwest economically and culturally distinct. This region is quite diverse in production capabilities, population densities, land use, level of state support, and local culture.

Seven of the 10 case studies fit the USDA definition and self-identified as food hubs. Of the remaining three, one identified as a transportation company and two as business incubators. For this study, we consider these three as food hubs because they offer food hub services or because the businesses they support offer these services and collectively fulfill a food hub role that the case study organization enables. Nonprofits in this study were founded and supported by local government agencies as an economic development strategy. We included one food hub that went out of business during this research, one in the planning and start-up process, and one that went through a planning process but has not yet launched. Table 1 provides an overview of the 10 case studies.

The case studies are based primarily on indepth interviews we conducted before and after the onset of the COVID-19 pandemic. We consider March 2020 to March 2021 the first year of the COVID-19 pandemic because significant impacts in the study area began during this period. We conducted the first round of interviews in 20182019 using a semi-structured interview guide with questions focused on history, organizational structure, sources of capital, and evolution. We asked about services, facilities, and equipment; constraints and opportunities for further development; and how demand has changed over time. We also 
Figure 1. Population Size of Case Study Food Hub Locations a

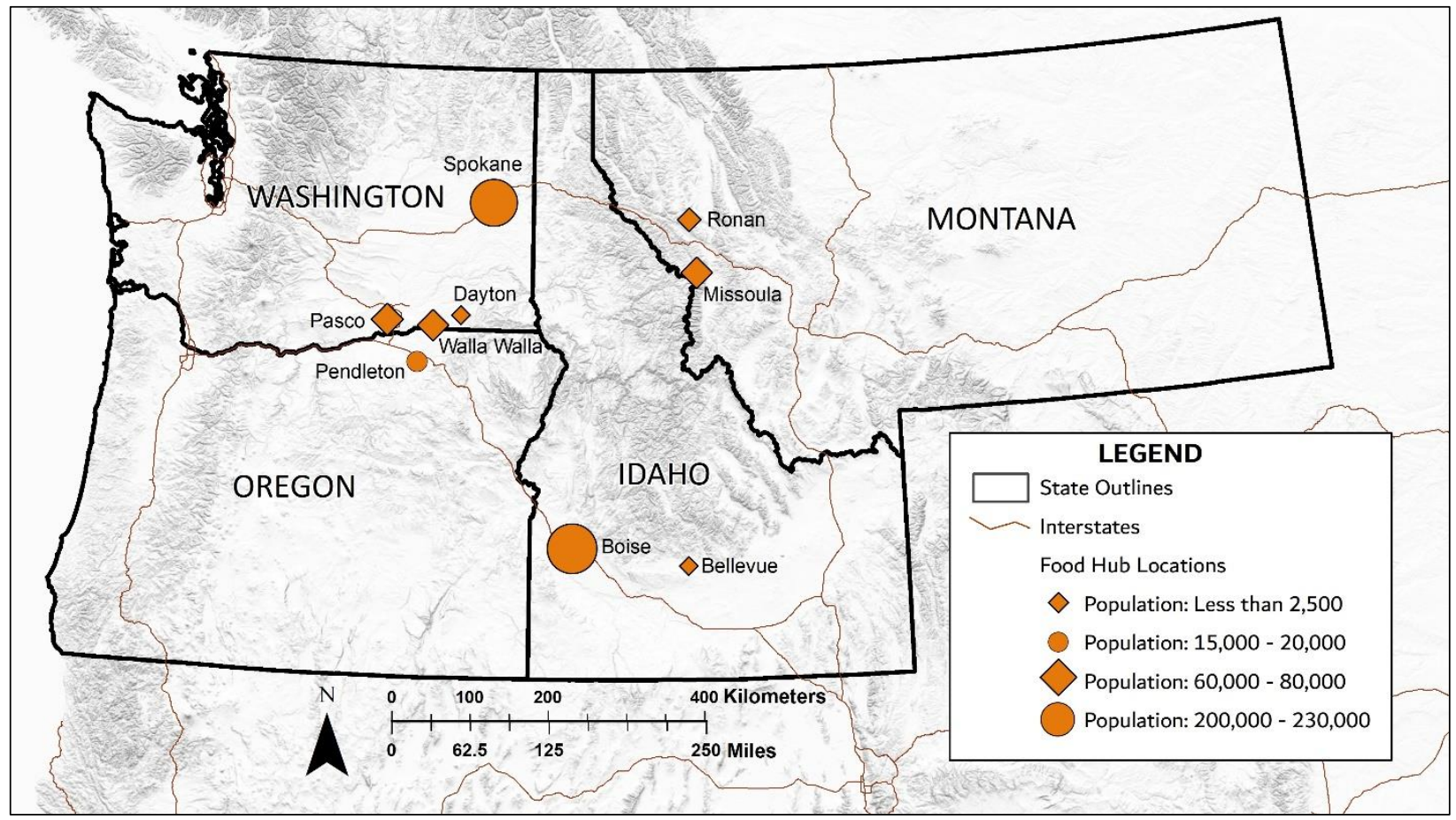

asked about the role of relationships, partnerships, and values in their business development. Finally, we asked about lessons learned and their planned next stage of development. Representatives from each case study reviewed and approved our description of their operation in early 2021, at which time the eight active food hubs indicated significant changes due to COVID-19. We followed up with an additional interview with these food hubs, asking them about their experiences during the first year of the COVID-19 pandemic, including the role of the USDA Farmer to Families Food Box Program (FFFBP) (part of the Coronavirus Food Assistance Program), U.S. Small Business Administration Paycheck Protection Program (PPP), and other COVID-19 relief funding; how COVID-19 had impacted their business model; and how their plans had changed. We conducted more than one follow-up interview for some, depending on the complexity of the operation and its evolution. Ultimately, case studies involved at least two interviews with at least one representative for a total of 23 food hub interviews with 24 participants.

We supplemented our food hub interview data with a review of publicly available information about each operation found online (e.g., websites, reports, and news stories). The case studies were also informed by 52 additional interviews involving 61 key informants representing positions throughout the food hub supply chains (i.e., producers, buyers, conventional food distributors, government agencies, and nonprofit organizations). These interviews focused on opportunities, barriers, distribution strategies, interests, motivations, relationships, and values related to participation in local and regional food supply chains. Interviews lasted approximately 60 minutes and were recorded and transcribed with permission. We analyzed all interviews using ATLAS.ti software following the process described by Charmaz (2006).

\section{Food Hubs in the Inland Northwest}

\section{Cooperatives}

\section{Local Inland Northwest Cooperative Foods}

Local Inland Northwest Cooperative Foods (LINC) is an employee- and farmer-owned cooperative food hub with approximately 50 members in 
Spokane, Washington. Until 2020, LINC's primary focus was to aggregate products from farmers within 250 miles $(402 \mathrm{~km})$ of Spokane and distribute them to wholesale buyers within a 3-hour drive. LINC also operates a community supported agriculture (CSA) service called LINC Box, which served approximately 130 consumers in the greater Spokane area in 2019. The cooperative offers quality assurance and a web-based ordering system for buyers, and liability insurance and for-fee minimal produce processing for farmers. In 2016, they launched LINC Malt, which makes small-batch malt for craft brewers and distillers.

LINC started in 2014 with few resources beyond an old vehicle and the co-founders' time. Early on, it transitioned from renting cold storage from a hotel to partnering with Second Harvest Food Bank for cold, frozen, and dry storage space before being able to afford its own warehouse facility. Using available resources (e.g., free office space in a church basement) and sweat equity, it focused on creating transactions to start the business and identifying resources for scaling up. To do so, it relied on grants and awards and generous and supportive friends and community organizations. Over several years, it built the capital and infrastructure needed to reach its current state of development: "[We built] the business organically figur-

\section{Table 1. Case Study Food Hub Overview}

\begin{tabular}{|c|c|c|c|c|}
\hline Case study & Model & Location and territory & Primary services & Years \\
\hline $\begin{array}{l}\text { Local Inland North- } \\
\text { west Cooperative } \\
\text { Foods }\end{array}$ & $\begin{array}{l}\text { For-profit farmer and } \\
\text { employee-owned coop- } \\
\text { erative }\end{array}$ & $\begin{array}{l}\text { Spokane, WA; serves } \\
\text { region within 3-hour } \\
\text { drive }\end{array}$ & $\begin{array}{l}\text { Aggregation, distribution, } \\
\text { value-added processing, } \\
\text { marketing }\end{array}$ & 2014-current \\
\hline $\begin{array}{l}\text { Western Montana } \\
\text { Growers Cooperative }\end{array}$ & $\begin{array}{l}\text { For-profit farmer-owned } \\
\text { cooperative }\end{array}$ & $\begin{array}{l}\text { Missoula, MT; serves } \\
\text { western MT }\end{array}$ & $\begin{array}{l}\text { Aggregation, distribution, } \\
\text { marketing }\end{array}$ & 2003-current \\
\hline Idaho's Bounty & $\begin{array}{l}\text { For-profit farmer and } \\
\text { consumer-owned coop- } \\
\text { erative }\end{array}$ & $\begin{array}{l}\text { Boise, ID; served } \\
\text { southern Idaho within } \\
\sim 3-5 \text {-hour drive }\end{array}$ & $\begin{array}{l}\text { Aggregation, distribution, } \\
\text { marketing }\end{array}$ & $2007-2018$ \\
\hline Blue Mountain Station & $\begin{array}{l}\text { Managed by Port of } \\
\text { Columbia }\end{array}$ & $\begin{array}{l}\text { Dayton, WA; serves } \\
\text { southeast WA }\end{array}$ & $\begin{array}{l}\text { Commercial kitchen, grocery } \\
\text { cooperative, business } \\
\text { incubation }\end{array}$ & 2013-current \\
\hline $\begin{array}{l}\text { Mission Mountain } \\
\text { Food Enterprise } \\
\text { Center }\end{array}$ & $\begin{array}{l}\text { Nonprofit managed by } \\
\text { Lake County Community } \\
\text { Development Corporation }\end{array}$ & $\begin{array}{l}\text { Ronan, MT; serves } \\
\text { western MT }\end{array}$ & $\begin{array}{l}\text { Co-pack, commercial } \\
\text { kitchen, value-added pro- } \\
\text { cessing, business incuba- } \\
\text { tion, technical assistance }\end{array}$ & 1998-current \\
\hline $\begin{array}{l}\text { Pasco Specialty } \\
\text { Kitchen }\end{array}$ & $\begin{array}{l}\text { Nonprofit supported by } \\
\text { the city of Pasco }\end{array}$ & $\begin{array}{l}\text { Pasco, WA; serves } \\
\text { Pasco area }\end{array}$ & $\begin{array}{l}\text { Commercial kitchen, busi- } \\
\text { ness incubation, technical } \\
\text { assistance }\end{array}$ & 2003-current \\
\hline $\begin{array}{l}\text { Walla Walla Valley } \\
\text { Food Hub }\end{array}$ & $\begin{array}{l}\text { Nonprofit/private } \\
\text { cooperative }\end{array}$ & $\begin{array}{l}\text { Walla Walla, WA; } \\
\text { expected to serve } \\
\text { Walla Walla Valley }\end{array}$ & $\begin{array}{l}\text { Value-added processing, } \\
\text { storage, co-pack, distribution }\end{array}$ & $\begin{array}{l}\text { In planning } \\
\text { and start-up }\end{array}$ \\
\hline $\begin{array}{l}\text { Pendleton Food Hub } \\
\text { (Proposed) }\end{array}$ & Nonprofit & $\begin{array}{l}\text { Pendleton, OR; plan- } \\
\text { ned to serve within } \\
250 \text { mi. (402 km) }\end{array}$ & $\begin{array}{l}\text { Commercial kitchen, ag- } \\
\text { gregation, distribution, } \\
\text { marketing, value-added } \\
\text { processing }\end{array}$ & Not active \\
\hline $\begin{array}{l}\text { Turning Point Trans- } \\
\text { portation }\end{array}$ & For-profit family business & $\begin{array}{l}\text { Walla Walla, WA; } \\
\text { serves central WA and } \\
\text { western ID }\end{array}$ & Aggregation, distribution & 2016-current \\
\hline $\begin{array}{l}\text { Kraay's Market and } \\
\text { Garden }\end{array}$ & For-profit family business & $\begin{array}{l}\text { Bellevue, ID; serves } \\
\text { Wood River Valley }\end{array}$ & $\begin{array}{l}\text { Production, aggregation, } \\
\text { distribution, marketing }\end{array}$ & 2013-current \\
\hline
\end{tabular}

Note: ID=Idaho; MT=Montana; OR=Oregon; $W A=$ Washington state 
ing out where we can borrow resources from other partners until we can pay for those things ourselves, and then strategically finding those grants that...allowed us to build the business." When it started in 2014, LINC had about $\$ 30,000$ in sales. ${ }^{1}$ In 2020, LINC's sales reached roughly $\$ 1$ million (Segerstrom, 2020).

Grants and awards have been instrumental to LINC's development, enabling it to purchase equipment and vehicles, hire staff, pay living wages, and otherwise leverage and sequence its expansion. For example, LINC hired a sales and marketing person with a $\$ 300,000$ USDA Specialty Crop Program grant. A USDA Value-Added Producers Program grant helped get the cooperative its own building. In addition, LINC won $\$ 25,000$ through a University of Washington business accelerator competition-unique among those we interviewed - to develop LINC Malt as a highermargin, value-added business with year-round revenues. The Washington State Department of Agriculture also helped LINC coordinate, network, train, and secure grants. Before 2020, LINC's fee of $25 \%$ of wholesale revenues for distribution and sales of member produce was an important source of capital.

The COVID-19 pandemic had a strong effect on LINC. LINC Malt was expected to grow dramatically in 2020 to provide the revenues LINC needed to become profitable, but sales were affected by the pandemic and held steady at the previous year's level. Adapting to the new context, LINC instead leveraged its experience and logistics for LINC Box to secure a first-round $\$ 100,000$ FFFBP contract that not only kept it afloat but enabled it to further develop capacity for serving higher-margin direct markets. It did not receive additional contracts from the FFFBP but transitioned to support ongoing county and state food security efforts. Concerning federal, state, and local food box programs that emerged in response to the pandemic, an interviewee said,

That's been a lifesaver for us ... what a cool vehicle to be able to invest in food systems and also give people access to great, healthy, fresh produce. ... Because of these box programs, we were able to move the same amount of produce [in 2020]. So yeah, there wasn't any shortfall or anyone we had to turn away.

The PPP was also important as it allowed LINC to cover its rent for about three months and hire back two staff members who had been laid off at the beginning of the pandemic. These programs also helped it prepare for a different business trajectory than it had envisioned a year earlier. During the first year of the pandemic, LINC switched focus to direct markets and transitioned out of wholesale. Many of its primary wholesale customers had been in higher education and restaurants, which were heavily affected by the pandemic. In addition, it expanded LINC Box and LINC Malt and launched LINC Marketplace, an online directto-consumer sales portal. Participation in food security efforts, a new strategy resulting from the pandemic, remains an important priority moving forward. As a result of these changes, 2020 was the first year LINC was profitable, and it expected to be so in 2021.

\section{Western Montana Growers Cooperative} Western Montana Growers Cooperative (WMGC) is a farmer-owned aggregation, distribution, and marketing food hub in Missoula, Montana, that started in 2003. WMGC distributes products, including produce, dairy, and meat, from 40 member and 40 nonmember producers in western Montana to wholesale markets and directly to consumers through their CSA, which accounts for $5 \%$ of sales. The cooperative has a web-based database to update products and track sales; however, four employees handle most sales via email or phone. While WMGC operates four trucks of its own, partnerships with other distribution companies have helped expand its territory:

We have our own trucks we run north and south, and then we partner with other distributors to go east to Butte, Bozeman, Helena, Billings, and west into Spokane and northern Idaho. And those partnerships with other dis-

${ }^{1}$ All values are in U.S. dollars. 
tributors is a real important part of our

business.

WMGC's annual capital includes $20-25 \%$ of sales revenues. A portion of its working capital comes from member loans, equity, and dues, which are $\$ 150$ for the first year and then determined on a sliding scale from $\$ 150$ to $\$ 400$ based upon a member's annual sales. For the first several years, WMGC's annual sales ranged from $\$ 20,000$ to $\$ 30,000$. At that point, it owned one truck and initially paid employees using grant funding. However, by year five, the operation was profitable with $\$ 500,000$ in sales. WMGC continued securing grants, which fueled growth. WMGC operated on a farm for the first 10 years and then moved into a centrally located warehouse in Missoula in 2014. The move cost $\$ 400,000$ and was financed with $\$ 100,000$ in grants, $\$ 100,000$ in loans from members, and $\$ 200,000$ in outside debt. Members are paid back through patronage dividends and equity shares at a rate of $\$ 40,000-\$ 50,000$ per year across the membership, with the intention to grow the amount distributed over time. WMGC is an example of a cooperative where a long-time manager and staff have led the organization through several evolutions to become a distribution company with $\$ 4.66$ million in sales in 2020 .

So far, the pandemic has strengthened WMGC, which grew $15 \%$ in gross sales in 2020 . It received $\$ 67,000$ of PPP funding early in the pandemic, which helped through several quarantinerelated closures. It also received a first-round FFFBP contract, which helped distribute products for members whose sales had been disrupted by the pandemic. For WMGC, the biggest impact of the pandemic resulted from a frenzy of consumer panic buying early on. This increased demand from retail customers cleared its surpluses and has used all members' production since. It has also led to increased distribution of nonmember products. WMGC had a business model and strategy that kept it profitable and growing over two decades, serving it well as it weathered and grew through the first year of COVID-19. WMGC saw the FFFBP as temporary support that helped it get through the first year of the pandemic, and it did not change its business model or planned trajectory as a result.

\section{Idaho's Bounty}

Idaho's Bounty was a farmer-owned aggregation, distribution, and marketing food hub cooperative that went out of business in 2018 after several restructuring phases over 11 years of operation. The cooperative served a vast swath of southern Idaho, including the Treasure Valley near Boise, the Wood River Valley near Ketchum, and the Magic Valley near Twin Falls. For a brief time, Idaho's Bounty made deliveries as far as Jackson Hole, Wyoming, and Salt Lake City, Utah. In addition to wholesale accounts, the food hub delivered directly to individual consumers. The intention was for customers to place orders through the Idaho's Bounty website, where farmers were responsible for updating their product availability and setting their prices. However, due to website complications, the cooperative hired sales representatives who managed many accounts and transactions by phone.

At its peak, Idaho's Bounty had approximately $\$ 630,000$ in annual sales; over 80 producer members; 1 full-time and 11 part-time employees; multiple trucks; and a facility with an office and dry, cold, and frozen storage. Start-up and operating capital were heavily reliant on donations from wealthy patrons looking to expand access to local, organic food in the Wood River Valley as well as loans from a limited number of farmer-owners. In addition, the cooperative relied on grants, a portion of sales revenues, and fees, credit, and equity invested by members. However, over time the cooperative became increasingly indebted to members. Idaho's Bounty was unique among case studies in attempting to use a public offering to raise money by selling shares to those beyond its membership. If the offering had gone through, Idaho's Bounty would have paid back loans, capitalized necessary equipment, and sought additional supply contracts. It focused on a public offering in part because of its poor financial performance. As one interviewee explained, "over the whole organization's period, no [banks] would give the organization any loans because they didn't like the financials."

Idaho's Bounty failed for several reasons from the perspectives of those interviewed. One said the cooperative had been too ambitious in hiring staff and purchasing equipment: "They sort of hired 
expensive people and bought a big truck and, all of a sudden, the overhead was crushing." One interviewee thought it had tried to solve basic business problems with grants rather than using grants to build and supplement the business. It also tried to serve a vast rural area with low population densities.

One lesson conveyed was the need for appropriate scaling of the operation to the revenues available:

It went from a little community thing to racking up a bunch of bills and needing to pay them, so [Idaho's Bounty was] expanding the wholesale and expanding services over the course of five years trying to expand, expand, expand and it not happening. And then finally it imploded.

However, according to one interviewee, the biggest contributor to Idaho's Bounty's failure was its members' lack of active participation in making decisions and covering costs. A small number of members made many of the decisions and, as members' need for services increased, many were unwilling or unable to contribute to cover costs. As fewer members contributed, resources were exhausted. Idaho's Bounty had five out of six attributes of successful food hubs identified by Feldstein and Barham (2017), including a business plan, professional staff with experience, a market assessment, and an understanding of the food production process. It also had many supportive partners. However, it could not secure a strong financial foundation despite many attempts to raise capital and expand operations. Idaho's Bounty provides an example of the risk involved in these types of ventures, with some producers losing money in the end despite the donations and grants; agency, nonprofit, and university support; and a lot of goodwill and helping hands.

\section{Government Agency}

\section{Blue Mountain Station}

Blue Mountain Station (BMS) in Dayton, Washington, terms itself a "destination eco-food processing park dedicated to the recruitment and marketing of artisan food processors, primarily in the natural and organic sectors" (2021, para. 1). The Port of Columbia originally envisioned the project to recruit large food processing businesses to Columbia County. However, during the planning process, it reoriented to support small, local businesses: "What demand we ended up seeing were very small processors, not demand from large businesses wanting to move or expand." It took seven years to go from conception to having an operational building. The first step was a marketing study funded by a program that no longer exists. The study suggested focusing development on the artisan food niche. Next, the Port of Columbia secured a $\$ 80,000$ grant for a feasibility study from the Washington Department of Commerce Community Economic Revitalization Board (CERB). It then secured $\$ 1$ million from CERB, which was matched with $\$ 100,000$ from the city of Dayton, Columbia County, Port of Columbia, Dayton Chamber of Commerce, and Pacific Power. This provided $\$ 700,000$ to buy and develop 28 acres in Dayton and about $\$ 380,000$ for infrastructure, such as city water, roads, and a parking lot, for the first eight acres. A significant portion of capital costs was paid with a zero-interest loan with a delayed payback to allow revenues to build during the first five years. The Port of Columbia also secured $\$ 750,000$ from the Washington State legislature through the Washington Public Ports Association and then raised the remaining $\$ 350,000$ needed to finish the first building through a local bond. The plan is that, once the debt is paid off, lease revenues will continue to fund expansion and operations.

BMS has been successful partly because the Port of Columbia secured resources only ports could access, including unique opportunities to receive state appropriations and local bond revenues. Equally important, BMS has fully rented its food business incubation space and has a waiting list of businesses ready to lease space as it becomes available. The organization recently constructed a new building, which was fully leased before completion. In addition, BMS rents a commercial kitchen for $\$ 10 /$ hour, which covers the cost of kitchen operations and contributes to the cost of a part-time manager. BMS also includes a grocery 
cooperative that leases space and sells fresh and value-added products from local farmers at a $20 \%$ commission, a year-round farmers market, and a restaurant, none of which were imagined during the project planning phases. Through BMS, the Port of Columbia is serving the role of a community-based organization connecting producers with local and regional markets. It attributes its success, in part, to working with the Washington State Department of Agriculture from the beginning to design the building. Lease revenues currently support building maintenance, debt service, improvements, and some staff. Its founder at the Port of Columbia had the knowledge, capacity, and energy to access and secure the mix of capital needed to develop the project this far.

BMS has continued to grow through the pandemic and is beginning the process of adding a third building. All businesses at BMS survived the first year of the pandemic, and several have thrived. The cooperative grocery store more than doubled its sales in 2020 and added home delivery. It attributes the growth in sales to strong new interest among community members previously unsupportive of BMS or local foods. Commercial kitchen use "exploded" in 2020, as has the need for cold and dry storage. Craft beverage makers at BMS suffered the most when they had to close their tasting rooms, and several received funding from the PPP and from Washington State that helped them remain in business until in-person sales resumed. No one at BMS participated in the FFFBP, although several supported Dayton Food Bank efforts. At the beginning of the pandemic, BMS was already at full capacity and needed more space. The first year of the pandemic has only increased its urgency to start on its next building. While BMS's primary mission is to incubate and support artisan food businesses, the businesses it supports deliver a range of food hub services, including marketing and sales, value-added processing, and food product development. BMS also directly provides food hub services by providing storage and shared equipment and resources for its tenants and direct-to-consumer marketing venues. BMS is also a hub of communication, coordination, and activity for food system development in the area.

\section{Nonprofit Businesses}

\section{Mission Mountain Food Enterprise Center}

Mission Mountain Food Enterprise Center

(MMFEC) is a community-based nonprofit food

processing, research, and business incubation facility. In 1998, a group of farmers partnered with the Lake County Community Development Corporation (LCCDC) in Ronan, Montana, to commission a food system assessment. The assessment, funded by a W.K. Kellogg Foundation grant, focused on regional agriculture-based economic development. LCCDC became home to the Cooperative Development Center for western Montana, providing technical assistance statewide due to the priorities identified, which included supporting cooperatives and building food-processing infrastructure. Funding from the USDA Rural Cooperative Development Program supported the launch of the Cooperative Development Center and a marketing plan for the newly envisioned MMFEC. As a result, LCCDC received one-time federal funding followed by one-time state funding over eight years to capitalize and develop the MMFEC, which in 2020 had $\$ 4.5$ million in revenues.

Staff, capital, and programs from the LCCDC and Cooperative Development Center have supported and helped sustain MMFEC's operation. Considerable synergy exists across the entities. The lessons the Cooperative Development Center has learned while supporting the creation of valueadded food cooperatives in the state (e.g., WMGC) have informed MMFEC's successful business evolution. Grant-based program work has built experience, knowledge, and skills among staff across the three entities while providing the base funding for long-term staff. Grants continue to pay for support staff and functions at MMFEC, including most equipment and facility improvements, while revenues support the employees directly involved in value-added food processing and copack operations.

Before the pandemic, MMFEC's co-pack operation had focused on supporting farm-to-school programs. But, due to changes in state-level support, school procurement had already dramatically dropped during the 2019-2020 school year. This 
gave MMFEC available capacity for co-packing food boxes for food security efforts when the pandemic began. Early on, it received $\$ 710,000$ of PPP funding, which helped it bridge an initial loss in revenues. It used the funding to transition its copack operation to the food box program. MMFEC started repackaging food for the Montana Food Bank and integrated into the Montana food security network. It also partnered with WMGC on its FFFBP application and built boxes for that project during its first-round contract. MMFEC has kept its food box program going with donations and a foundation grant.

Throughout its history, LCCDC's status as a county-level economic development agency adept at accessing state and federal resources made it uniquely well-positioned to take advantage of available funding opportunities: "As a [projectdriven] nonprofit ... we were able to tap into those funds and get new programs rolling out." It was the right organization, with the right amount of capacity, to take advantage of new government funding programs:

All these other policies and priorities that were coming down from the federal level and the state level. I mean [the] ... USDA Local Food Promotion grant program, Farm-to-School grant program, [and] Specialty Crop grant became really focused on local food. All of a sudden, all of these federal policies were being rolled out, and they were huge support mechanisms to operations like ours.

Now, after the first year of the COVID-19 pandemic, LCCDC has added donations, foundation grants, and fees from new clients as sources of capital.

MMFEC sees this transition towards food security and new sources of capital as a long-term shift in its trajectory. The nonprofit expects to expand co-pack and support services for producer cooperatives in the region as part of food security efforts. Its experience with co-packing food boxes also gave it experience in direct-to-consumer markets, where before its focus had been direct-toinstitutions. MMFEC is building on this experience to develop an online direct-to-consumer market- place. It is also exploring developing retail space and a restaurant, which it sees as the next steps in supporting local job growth and economic development.

As the oldest effort in our sample, MMFEC has navigated major changes in the availability of resources at federal, state, regional, and local scales. In doing so, it has overcome challenges to thrive in a remote rural area in northwest Montana. Moreover, as its response to the COVID-19 pandemic demonstrates, MMFEC continued to adapt to rapidly changing circumstances and available funding.

\section{Pasco Specialty Kitchen}

Pasco Specialty Kitchen (PSK) is another example of a successful agency-supported, nonprofit business incubator that provides direct-to-consumer food hub services, including a farmers market, a walk-up sales window, and marketing services. The businesses it supports provide additional services, such as value-added processing and wholesale and direct-to-consumer sales.

In 1985, business owners in Pasco, Washington, created the Downtown Pasco Development Authority (DPDA). DPDA joined with the Pasco Main Street Program in 2002 to create PSK as an independent nonprofit aimed at revitalizing downtown Pasco (DPDA, 2021a). As part of this effort, the city of Pasco built a 12,000-square-foot facility for PSK that includes 10,000 square feet of commercial kitchen space for use by entrepreneurs developing manufactured, packaged, and commercial food products (DPDA, 2021b). In addition to providing fledgling businesses access to equipment and facilities, PSK provides technical assistance, free vendor space at farmers markets and other events, connections to other businesses and services, and meeting and classroom space.

PSK has also been active in connecting the businesses it supports to Craft3, a regional nonprofit community development financial institution (CDFI) that provides loans to start-up and growing businesses that do not qualify for traditional loans, and the Oregon Association of Minority Entrepreneurs. PSK's goal is to move businesses to operate fully on their own within three years. In 2019, PSK had 39 clients. About half were mobile food vendors who relied on PSK's equipment and facilities 
to meet state health requirements. In early 2021, PSK had 16 clients but is in a stronger position than before.

PSK was initially funded by the U.S. Department of Commerce Economic Development Administration (EDA) Program and the Community Development Block Grant (CDBG) program of the Washington Department of Housing and Community Development, managed by the city of Pasco. Currently, the city provides a tax credit, reimbursement for some expenses, and free rent as the remaining public support for PSK, which amounts to about $25 \%$ of its annual capital. As part of the pivot away from long-term federal funding, PSK is increasingly supported through revenues and several large private foundation grants, reflecting and shaping additional change. The city of Pasco remains an important funder, but PSK is largely operating as an independent nonprofit business and is actively growing non-public revenues. Its current budget is nearly $\$ 600,000$, with $\$ 157,000$ from the city of Pasco, $\$ 400,000$ from private foundations, and the remainder from other sources, such as donations and fees.

In response to COVID-19, PSK has further focused its value proposition and business model to support Latinx entrepreneurs, many of whom are immigrants, and Latinx community-building. As part of COVID-19 relief funding, PSK received a grant that included $\$ 228,000$ regranted to clients as minigrants. The nonprofit also hired more bilingual and bicultural staff, dropped costly business support services (e.g., accounting and legal services), created two recording studios for radio and video marketing and podcasting, and refocused more narrowly on business start-ups. The COVID-19 crisis catalyzed change that had been long needed from the perspective of one interviewee:

Before COVID [it] was nearly impossible [to change course] because we were so busy with so many other things that, [due] to COVID, we were able to relax, step back a little bit and focus on all these equipment and ... media that it's actually fostering that sense of belonging and community for the Latinos.
PSK partially redefined its service population, value proposition, and approach as it adapted during the first year of the COVID-19 pandemic.

\section{Walla Walla Valley Food Hub (Proposed)}

The Blue Mountain Action Council Food Bank (BMAC), based in Walla Walla, serves five counties in southeast Washington. Working with the Walla Walla Valley Food System Coalition (WWVFSC), BMAC received a $\$ 100,000$ USDA Local Food Promotion Program (LFPP) grant for a food hub feasibility study that was completed just as the pandemic began (Saul et al., 2020). BMAC hoped a private cooperative food hub would provide the processing and co-packing it needed and that together they could leverage a larger shared facility and improved economies of scale. However, $\mathrm{BMAC}$ received funding during all three rounds of COVID-19 relief, which changed its plans. It received \$2.4 million from the CARES Act in the first round and $\$ 770,000$ from the Consolidated Appropriations Act. BMAC's award from the American Rescue Plan will take care of the rest of its facility and vehicle needs. As a result, BMAC has doubled the size of its facility, tripled freezer space, increased cold storage, and added three new refrigerated trucks and a refrigerated van, thereby achieving all the facility and vehicle needs identified in the feasibility study. The FFFBP has also been crucial for its rapid growth as it addresses increased food assistance needs. BMAC is still supportive of the development of a food hub but no longer thinks it is appropriate on its site due to needing the full capacity of the facility as well as logistical and safety concerns.

In the meantime, when it was clear that local farmers markets would not be viable during the pandemic, Hayshaker Farm — an active participant in the WWVFSC - launched an online market and began distributing products from other local farms and a few items from other areas in Washington. At the end of the first year of the pandemic, it has reached its capacity for on-farm food hub activities and is ready to move into a larger facility. The pandemic has stimulated rapid growth and adaptation for BMAC and Walla Walla Valley producers, triggering the launch of a family-owned food hub and access to federal funding that supported BMAC's 
expansion. Activities are underway to leverage these advancements into a larger cooperative food hub that meets remaining producer goals.

\section{Pendleton Food Hub (Proposed)}

In 2014, a partnership of local agencies and nonprofit organizations started a food hub planning process in Pendleton, Oregon. It was meant to serve Umatilla, Morrow, Gilliam, and Wheeler counties in Oregon. Their plan included providing aggregation, storage, distribution, marketing, food processing, a commercial kitchen, and a storefront deli. They were also interested in including consumer education and workforce development, health-care services, and childcare as part of the facility. During one phase, Meyer Memorial Trust funded a three-year statewide project to bring all the players together to identify niches, gaps, and opportunities for investment or philanthropic support for food system development, which helped move the Pendleton effort forward. Meyer Memorial Trust also provided a $\$ 300,000$ grant to develop food systems in three counties. Despite several planning efforts, some producer interest, and regional and statewide nonprofit, agency, and extension support, the Pendleton Food Hub is still looking to gain traction. Challenges have included identifying skilled and committed people, getting buy-in from enough producers, a depressed local economy, and obtaining enough funding to establish the infrastructure necessary or carry out the next steps. For example, the effort has identified buildings in Pendleton suitable for a food hub but has not advanced the process to purchase one.

One interviewee thought a constraint was that the producers in the Pendleton area are too big to care about the development of a food hub. Also, they felt a constraint was that much of the agricultural area in these counties cannot be irrigated and is primarily dryland crops or livestock range, with produce production limited to small river valleys with more water. Another problem identified is a lack of local sales venues. For example, 17 grocery stores have consolidated into three in Pendleton; Wheeler County does not have a grocery store, which means people must drive 20 miles or more to the nearest one; and existing grocery stores buy little or no local produce. Another constraint iden- tified was that economic development projects have focused on large-scale export commodities and do not support smaller producers, resulting in few local governmental supports. One interviewee thought that since the four counties have such low population densities, they need to develop a regional operation at a scale large enough to interest the larger producers while still providing access to smaller producers. They also identified producer mistrust as a constraint. They suggested buying a truck or another tangible asset so producers could see a food hub would be viable, thus reducing the perception of risk.

\section{Family Businesses}

\section{Turning Point Transportation}

Turning Point Transportation, LLC (TPT), is a trucking business based in Walla Walla, Washington, that transports produce from the field to buyers throughout eastern Washington and western Idaho. This was the smallest of the operations we studied, and the owner did not see the company as a food hub, although others identified it as providing food hub services. After being involved in trucking for over 30 years, the owner branched out on his own in 2016. The owner bootstrapped TPT from personal experience and finance strategies, including a vehicle loan, credit card, and line of credit at a commercial bank. Activities include aggregation via on-farm pickup and distribution to the first point of storage or processing. To supplement this work, TPT also moves heavy equipment and products for a large food processing company in the off-season. The owner occasionally provides producers with short-term storage in his trucks, and he expects to add a third truck soon dedicated to moving grain. Shortly after launching, the owner refocused TPT to a social entrepreneurship orientation. TPT's mission is to allow veterans to gain work experience after leaving the service. TPT has had no direct public funding and is an example of a business starting as a conventional one and then gaining a social focus as it evolves, similar to the example cited by Avetisyan and Ross (2019).

While TPT experienced a lull in business at the beginning of the COVID-19 pandemic, it was short-lived. As consumers started panic buying, a 
large local retailer needed extra trucks to move products. This "windfall," plus a $\$ 13,000$ PPP loan to pay wages to enable use of the second truck, carried TPT until the cherry season, and it had near-normal work moving produce through the rest of 2020. In addition, one of TPT's main customers became involved in the first round of the FFFBP, and TPT served as its produce supplier. During the second round of the FFFBP, however, TPT combined forces with two other local businesses to win the bid to move produce from all of eastern Washington to two centralized locations where the boxes were created. These activities replaced any work TPT lost due to the pandemic and were expected to continue until the cherry season starts in 2021.

\section{Kraay's Market and Garden}

Kraay's Market and Garden is a family-owned business in Bellevue, Idaho, that serves the surrounding Wood River Valley, a high-margin, tourist- and amenity-rich area. Kraay's started as a family farm in 2015 and then quickly expanded to include services for other producers, becoming Idaho's first USDA-recognized food hub. The Wood River Valley's isolated geography has helped funnel the region's small producers through Kraay's to reach local direct-to-consumer and intermediated markets, including retailers, restaurants, and institutions. By 2019, Kraay's was picking up products from more than 50 farms. It also provided home delivery on rural routes as part of its on-farm pickup and delivery system. In addition to aggregation and distribution, Kraay's provides marketing and billing services. Its online ordering system has a weekly schedule that provides predictability to both producers and buyers. Kraay's hired several employees to keep up with growth and recently added a walk-in cooler.

As its business has expanded, Kraay's has adapted to grow produce on its farm desirable to buyers but not grown by other producers. The growing season in the Wood River Valley is short; in addition to outdoor growing space, Kraay's has three commercial greenhouses, two of which are heated for year-round production. Kraay's communicates regularly with its producers about what is in high demand and short supply and has en- couraged several to start producing year-round. It has also started distributing value-added and meat products. Kraay's hosts events, including farm tours, kids' activities, and produce vending, twice per year for its vendors, customers, and community members to strengthen existing relationships and build new ones.

In the early days of the pandemic, the Wood River Valley had one of the highest per capita rates of COVID-19 infection in the nation. Nearly everything in the valley shut down, including the Sun Valley ski resort, but Kraay's website orders exploded: "That first weekend, after everything shut down, I opened the store at eight o'clock and I had to close it at noon that day because I had 350 orders. We were used to doing about 100.” Its customer base expanded dramatically through word of mouth as people looked for ways to buy food without leaving home. Panic buying was evident, with one customer placing an order worth $\$ 1,900$.

Kraay's pivoted quickly to address the increased demand. It purchased a refrigerated trailer, took on volunteers looking for ways to help the community, and hired a part-time driver. It found that 250 orders per week was optimal and adjusted its capacity to meet this new level of business. As winter set in, orders decreased to about 180 per week, but Kraay's planned to resume 250 orders per week once the regular growing season began. At least two restaurants that sell value-added products through Kraay's website would have gone out of business, and several would have had to lay off more employees, without this income. Kraay's also collects donations on its website to cover the cost of providing food boxes to 10 to 15 families each week.

Kraay's built its business out of existing private resources and relationships without grant funding, public support, or loans. Moving forward, it plans to expand its aggregation and distribution activities, add a commercial kitchen, and increase community education efforts. The pandemic-motivated federal funding programs, such as the FFFBP, did not play a role in Kraay's expansion during the first year of the crisis. Instead, Kraay's growth was initially driven by direct-to-consumer panic buying that expanded its 
customer base and sales volume to an optimal scale for the operation.

\section{Access to Capital and Value Propositions} The development trajectory of these businesses and organizations reflects the opportunities available to them, the people involved, the capital available, and their social value proposition. WMGC and Idaho's Bounty started with producers pooling their private resources and agreeing to work together to access new markets. A small group of founders bootstrapped LINC into existence to advance more equitable local food systems. Staff at county and city economic development agencies started community-based nonprofits to advance community-level economic development goals. The Walla Walla Food Hub pulled together multiple ongoing efforts by producers and nonprofits to address a range of needs by diverse stakeholders. The Pendleton Food Hub planning effort identified community needs but has been unable to secure local support for the next steps. In contrast, the family businesses leveraged their food hub start-ups from existing businesses, relationships, and assets or personal credit. All had a unique mix of people, resources, value proposition, and context. The constant among the operating food hubs has been flexibility and rapid adaptation rather than a common start-up strategy, base of resources, or business model.

Grants served many financial purposes in cooperative, agency, and nonprofit food hub development but none directly for the family businesses (Figure 2). All the cooperatives received federal and state funding either as the main recipients or as beneficiaries and participating partners in larger grants spearheaded by public agencies and universities or colleges. Although grants have been instrumental to survival and growth for LINC, WMGC, and the Walla Walla effort, these organizations' goal has been to operate on revenues and use grants, in-kind support, and other resources to accelerate growth and support sustainability rather than to fund basic operations. Interviewees from Idaho's Bounty suggested that an overreliance on donations and grants masked problems with the organization's basic business model: specifically, that it was not profitable.

The cooperatives also all received in-kind support from local and state agencies, universities and colleges, and nonprofit organizations (e.g., food banks). In addition, the cooperatives integrated their members' private resources, and the private family food hubs integrated their family resources, strategies unavailable to agencies and nonprofits. Being a cooperative enabled them to draw from a wide array of resources in addition to business sales and loans.

The value propositions differed considerably
Figure 2. The Role of Grants in Cooperative and Nonprofit Food Hub Development

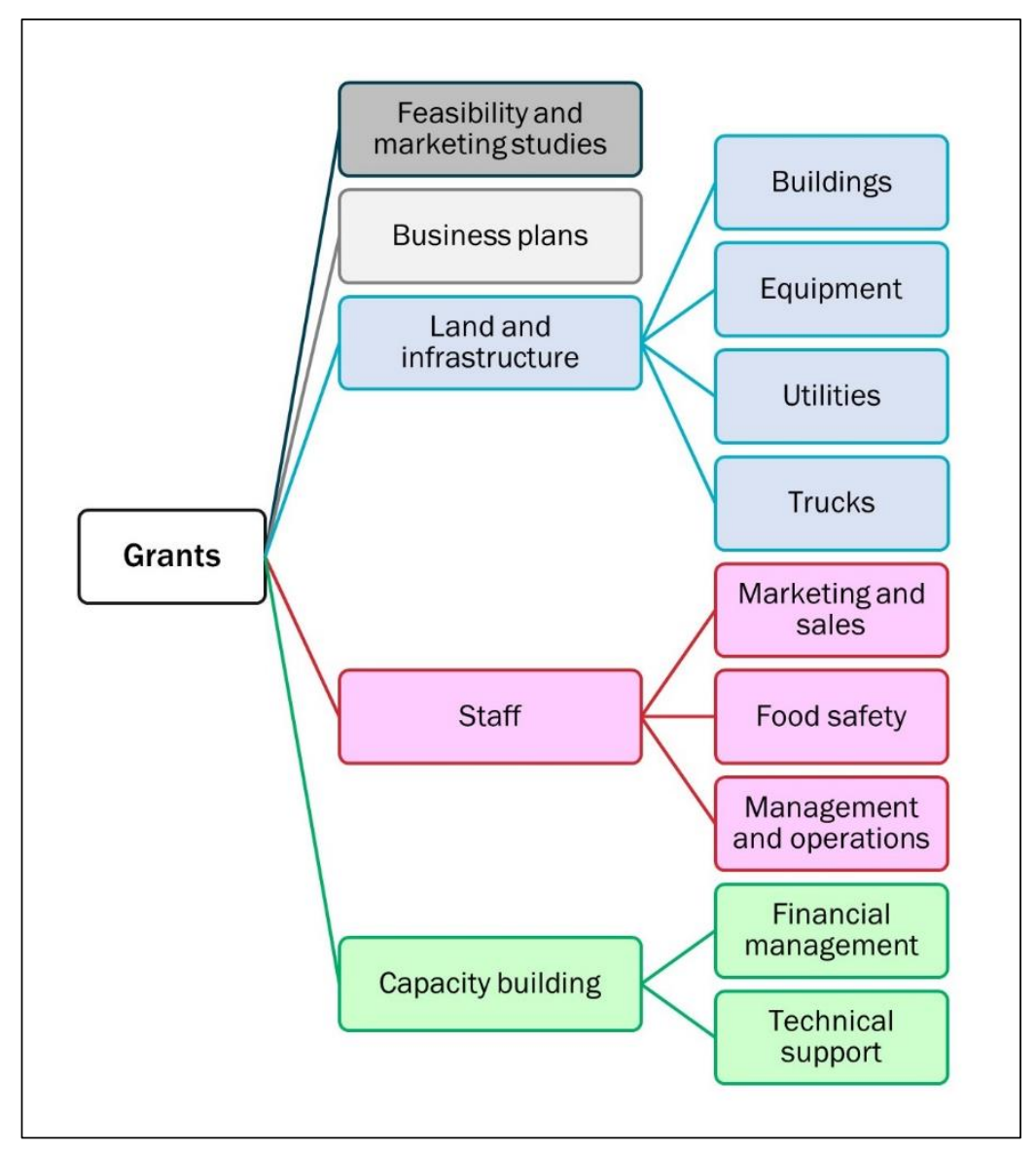


by business structure, but all the food hubs tried to advance nonmonetary goals. The cooperatives were dedicated to transparent and equitable supply chains and other social and environmental values but primarily focused on providing producers profitable market access. LINC expanded the cooperative ownership model to include employees as members. The agency and nonprofit food hubs were intentionally tasked with unprofitable work to support business development rather than be stand-alone, profitable businesses themselves. The focus and mission of the agency and nonprofit hubs also reflected their context, as all three worked in disadvantaged communities: two in lowpopulation rural areas and one in a low-income, economically distressed urban area. Context affected their mission and resource availability, reducing access to some types of local resources while making them eligible and competitive in securing state and federal funding. For the family businesses, being profitable was a non-negotiable value. Still, both had strong value propositions that shaped their activities, and both increased their focus on generating social value as their businesses grew. Agencies and nonprofits fulfilled roles of private food hubs in some rural and economically distressed areas, and private food hubs fulfilled agency and nonprofit roles in others.

\section{Effects of the COVID-19 Pandemic}

One year into the pandemic, all case study food hubs held steady or had higher profits than in the previous year. Federal, state, and local COVID-19related programs were instrumental in offsetting revenue losses resulting from the pandemic. The PPP played a critical role for several, in large part because salaries were not tied to a specific workload. MMFEC and LINC used PPP funding to shift from wholesale to direct-to-consumer markets. PSK used PPP funding to refocus on Latinx business start-ups, marketing, and communitybuilding. PPP funding gave all three time to reorganize their facilities, build new partnerships, and shed unprofitable operations to become more competitive and profitable than before the pandemic.

The FFFBP was as important as the PPP for the survival and strategic development of several food hubs. LINC, MMFEC, and TPT all pivoted to participate in the FFFBP and other local and regional food security programs as part of their pandemic adaptation. For WMGC, participation was minor compared to its overall operating budget. However, WMGC's participation in the FFFBP affected MMFEC, which retooled, built new partnerships, diversified funding, and translated its co-pack operation to food security efforts. Participating in local, statewide, and regional food security efforts is now a priority for both MMFEC and LINC.

For LINC, the FFFBP provided a lifeline through the first summer of the pandemic. LINC was especially hard hit because it centered on higher education and restaurants as its wholesale markets. However, the organization successfully transitioned to more profitable opportunities that strengthened its business. The loss of restaurant markets was less impactful for WMGC because it was better established than LINC, and a large portion of its business was wholesale to grocery stores, which experienced consumer panic buying and increased interest in local and regional products. Federal COVID-19-related programs were critical to the survival and growth through the first year of the pandemic for one family business, but not the other; and like WMGC, they both benefited from panic buying early in the pandemic and sustained increased demand in direct-to-consumer, food security, and wholesale channels.

\section{Conclusions}

This paper makes several contributions to existing knowledge about food hubs and local and regional food systems development. It includes data collection and analysis in the years immediately before and during the COVID-19 crisis, enabling us to analyze the early impacts of the pandemic, the role and benefit of public programs in local and regional food systems, and the adaptation of food hubs in response. The Federal Coronavirus Food Assistance Program played a limited but instrumental role for most in stabilizing, growing, and refocusing their activities. Although only TPT participated in later rounds of the FFFBP, the surge of funding at the local level during the first round better connected our case study food hubs 
to local and regional food security efforts and led to an overall increase in demand. The federal programs provided resources directly and indirectly for the food hubs to retool, build new relationships, and pivot to new opportunities. Hopefully, the need for food assistance programs will decrease as the pandemic subsides, employment improves, and stimulus funding disappears. Some heavily impacted markets will return, which will provide additional opportunities for new growth, competition for consumers, and further research opportunities.

For many, the pandemic increased interest in local and regional food systems as an important part of local resilience and highlighted weaknesses of national and global supply chains. Leveraging new scales of development from increased participation in local and regional food systems is an important next step. Understanding how these factors will affect future food hub business trajectories and local and regional food systems development is worthy of continued research.

Our exploration of agency and nonprofit roles in delivering food hub services in economically challenged areas where private and cooperative business models have less opportunity also breaks new ground. Few people in these areas know the USDA definition of a food hub. The term is a bucket for a wide variety of intermediary players connecting local producers and entrepreneurs to local and regional markets. The role of a food hub includes coordinating, supporting, and spearheading these efforts, which is a role agencies and nonprofits are fulfilling in some areas. These organizations can be understood in terms of multiple systems. Their role in local food systems development, including developing the services that cooperative and private food hubs provide elsewhere, is critical, especially in disadvantaged areas. But rather than delivering all services themselves, their impact is also through the businesses they enable to provide these services. Because of their greater access to and integration of private foundations and public resources, they can thrive in areas where local resources are insufficient to support a privately owned hub. Their value proposition, legal structure, and business model work well for this type of development in this type of context. They play a synergistic role with private food hubs in connecting local production to local and regional consumers in disadvantaged areas. Expanding this research to include other complex disadvantaged areas, such as Native American reservations, remote rural areas, and areas with a concentration of immigrants, are the next steps in understanding the interaction of people, context, and capital in successful local food systems development that advances multiple monetary and nonmonetary goals.

We found that adaptation has been key to developing successful food hubs, and most case study food hubs have refocused their business approach more than once. The mix of available capital for any particular hub reflected the people involved, the resources they recruited, and their specific local and state context. For the cooperative, agency, and nonprofit food hubs, grants were a part of their business model, and their success depended upon securing them. While grants have enabled growth, some have also been a challenge to dismount. Some activities and programs started with grants that seemed critical at the time but did not make sense once the grant ended and needed to be cut. Those with grants central to their business model tried to braid multiple grants, donations, volunteers, in-kind services, and other revenues to resource their operation in a way that provided the flexibility and stability they needed.

While the pandemic has been stressful and tumultuous, the operating food hubs we studied have demonstrated great agility and resilience in successfully navigating change and disruption. As opportunity changed during the pandemic, they grew in their role of connecting small and midsized farms to consumers and intermediated buyers. For some, the pandemic forced hard choices, which led to new opportunities and business models and a stronger business or organization, enabling those involved to advance social goals as well as economic ones. The growth of food hubs during the first year of the pandemic reflects not only their adaptive capacity as businesses but also their success as social enterprises advancing social values. The pandemic has catalyzed change that will have lasting impacts on local and regional food systems along with the people and communities they feed. 


\section{Acknowledgments}

We thank Steve Peterson and Malea Saul for their contributions to related projects that helped inform this effort. We thank Colette DePhelps, Nolan Lockwood, Jennie Dickinson, Jeff Mathias, and Jennifer Kleffner for introducing us to many of the people interviewed. We thank the many interview participants for generously sharing their time and experience. We thank Debbie Gray for providing the location map and Tenley Burke for helping proof-read the manuscript.

\section{References}

Austin, J., Stevenson, H., \& Wei-Skillern, J. (2006). Social and commercial entrepreneurship: Same, different, or both? Entrepreneurship Theory and Practice, 30(1), 1-22. https://doi.org/10.1111/j.1540-6520.2006.00107.x

Avetisyan, T., \& Ross, R. B. (2019). The intersection of social and economic value creation in social entrepreneurship: A comparative case study of food hubs. Journal of Food Distribution Research, 50(1), 97-104. https://doi.org/10.22004/ag.econ.292189

Bielaczyc, N., Pirog, R., Fisk, J., Fast, J., \& Sanders, P. (2020). Findings of the 2019 national food bub survey. Michigan State University Center for Regional Food Systems \& Wallace Center at Winrock International. https://www.canr.msu.edu/resources/2019-food-hub-survey

Blacher, R., \& Fields-Kyle, N. (2021). Nimble in a pandemic: Lessons learned from Concrete Jungle's Grocery Delivery Program. Journal of Agriculture, Food Systems, and Community Development, 10(2), 1-4. https://doi.org/10.5304/jafscd.2021.102.011

Blue Mountain Station. (2021). About BMS. https://www.bluemountainstation.com/about-bms/

Charmaz, K. (2006). Constructing grounded theory: A practical guide through qualitative analysis. SAGE.

Downtown Pasco Development Authority [DPDA]. (2021a). About us. https://www.downtownpasco.org/about-us.html DPDA. (2021b). Pasco Specialty Kitchen. https://www.downtownpasco.org/pasco-specialty-kitchen.html

Feldstein, S., \& Barham, J. (2017). Running a food bub: Learning from food bub closures (Service Report No. 77, Volume IV). United States Department of Agriculture. https://www.rd.usda.gov/content/sr-77-running-food-hub-volume-4-0

Matson, J., Sullins, M., \& Cook, C. (2013). The role of food hubs in local food marketing (No. 73). USDA Rural Development Service. https://www.rd.usda.gov/files/sr73.pdf

Morgan, T. (2015, July 1). A food hub grows in Gem County. Boise Weekly, 24(10), 24.

Neal, A. (2017, February 21). Food hubs_-Building businesses and sustaining communities. USDA Blog. https://www.usda.gov/media/blog/2013/11/20/food-hubs-building-businesses-and-sustaining-communities

Ollove, A., \& Hamdi, S. (2021). Activating the local food system in emergency food response. Journal of Agriculture, Food Systems, and Community Development, 10(2), 1-3. https://doi.org/10.5304/jafscd.2021.102.006

Ostrom, M., De Master, K., Noe, E., \& Schermer, M., (2017). Value-based food chains from a transatlantic perspective: Exploring a middle tier of agri-food system development. International Journal of Agriculture and Food, 24(1), 1-14. https://doi.org/10.48416/ijsaf.v24i1.112

Saul, D., Newman, S., Peterson, S., \& Saul, M. (2020). Walla W alla Valley food bub feasibility study. Arrowleaf Consulting. https://www.arrowleafgroup.com/past-clients

Segerstrom, C. (2020, November 1). Northwest co-op builds for a local food future beyond big ag. High Country News, 52(11), 30-37. https://www.hcn.org/issues/52.11/north-food-northwest-co-op-builds-for-a-local-food-future-beyond-big-ag

U.S. Census Bureau. (2019). Population and housing unit estimates. https://www.census.gov/programs-surveys/popest.html

U.S. Department of Agriculture Agricultural Marketing Service [USDA AMS]. (2021). Local food directories: Food hub directory. https://www.ams.usda.gov/local-food-directories/foodhubs

U.S. Geological Survey [USGS]. (2021). The national map: 3D elevation program. USGS Earth Resources Observation \& Science Center: GMTED2010. https://www.usgs.gov/core-science-systems 